\title{
Effect of Lightning Surge in AC Power and Telecommunication Lines for Electrical Devices
}

\author{
Yanuar Z. Arief \\ (1)Dept. of Electrical and Electronic Eng., \\ Faculty of Engineering \\ Universiti Malaysia Sarawak (UNIMAS) \\ Kota Samarahan,, Sarawak, Malaysia \\ ayzulardiansyah@unimas.my \\ (2) Master of Engineering Program, \\ Department of Electrical Engineering, \\ Faculty of Engineering, \\ Jakarta Global University (JGU), \\ Grand Depok Citi, Jl. Boulevard Raya 2, \\ Tirtajaya, Sukmajaya, Kota Depok, \\ Indonesia
}

\author{
Abu Arif Jalaluddin \\ Institute of High Voltage \& High Current \\ Faculty of Engineering \\ Universiti Teknologi Malaysia (UTM) \\ 81310 Johor Bahru, Johor, Malaysia \\ mr.abuarif@gmail.com \\ Lakshmanan Gurusamy \\ Dept. of Electrical and Electronic Eng., \\ Faculty of Engineering \\ Universiti Malaysia Sarawak (UNIMAS) \\ Kota Samarahan,, Sarawak, Malaysia \\ glakshmanan@unimas.my
}

\author{
Mohd Hafiez Izzwan Saad \\ Dept. of Electrical and Electronic Eng., \\ Faculty of Engineering \\ Universiti Malaysia Sarawak (UNIMAS) \\ Kota Samarahan,, Sarawak, Malaysia \\ smhizzwan@unimas.my \\ Hamzah Eteruddin \\ Dept. of Electrical Engineering, \\ Faculty of Engineering \\ Universitas Lancang Kuning (UNILAK), \\ Jl. Yos Sudarso, KM 8 Rumbai, \\ 28265 Rumbai, Riau, Indonesia \\ hamzah@unilak.ac.id
}

\begin{abstract}
Lightning surge phenomenon has been recognized as one of a threat to electrical and electronics devices. This event can cause degradation to the devices performance and at high energy can cause the total failure in devices operation. This research work objective is to observe and monitor the effect of lightning surge to electrical devices especially through their power lines and telecommunication lines port. The surge immunity test was conducted using lightning surge simulator to evaluate the immunity of electrical equipment such as multifunction printer, laser fax and integrated telephone systems to ensure them continues reliability operation. Variable voltage values have been injected to electrical devices in an increasing value up to $15 \mathrm{kV}$ or until the devices cannot withstand the voltage and start to degrade, temporary lost function and totally lost function. The devices performance and behavior has been monitored at the normal performance until abnormality performance has been observed and amount of voltage value at that time were recorded for analysis purpose. From this experiment, the high functional devices such as multi-function printer had the lowest immunity to the surge value followed by laser fax and lastly is integrated telephone systems. It was shown that the degradation and damage would occur if there were some narrow coincidence between the phase angle of waveform and superposition of surge. In this case, the frequently occur at phase angle of $90^{\circ}$ and $270^{\circ}$, respectively. The results revealed that the worst and high probability for damage to occur towards coupling/decoupling network is at common mode compare to differential mode (L-PE \& N-PE).
\end{abstract}

Keywords-Lightning surge, AC power line, telecommunication line, electrical devices, surge immunity simulator

\section{INTRODUCTION}

Lightning events such as lightning surge phenomena and lightning discharges cause a surge from voltages and current to produce. This event is recognized as a threat to electrical and electronics devices because can cause the device degradation and failure to operate. At a certain level such as high energy, it can cause device to breakdown. When negative electric charges generate in a thunderstorm discharges to the ground the lightning phenomena occur as a result of dielectric breakdown in the air [1-3].
This lightning event causes a surge voltage through the cable lines and transmits a momentary high voltage impulse to the inputs of computers and instruments in the control room or to sensors/transmitters in the field. The abnormally high voltage that generated by direct lightning discharge applied to electric power cables or communication cables at that instance times were defined as 'direct lightning surge'. The voltage induced by electrostatic or electromagnetic induction on those cables located close to the point where direct lightning hits were defined as induced lightning surge' [4].

Electromagnetic compatibility (EMC) is the branch of electrical sciences which studies the unintentional generation, propagation and reception of electromagnetic energy. Surge immunity testing is one of the scopes for EMC. For electrical and electronics devices, all the devices are required to pass the EMC standard before introducing and sale to the market and customer [5]. The standard for surge immunity testing is IEC 61000-4-5. This standard explains immunity requirement, test methods, and range of recommended test levels for equipment to unidirectional surges caused by over voltages from switching and lightning transients. These requirements are developed for and are applicable to electrical and electronics equipment. The objective of this standard is to establish a common reference for evaluating the immunity of electrical and electronic equipment when subjected to surges [6-7].

This investigation study on the possibility equipment to be degraded by the exposure of surge is very important due to unpredictable nature of lightning strike. The data and information obtained from this project would contribute towards standards implementation for surge protective devices.

\section{METHOD}

\section{A. Equipment Analytical Hierarchy Process}

The main equipment in this research work is surge immunity simulator (LSS-15AX C1A model). This equipment can generate two types of combination surge, 
namely $1.2 / 50 \mu \mathrm{s}(8 / 20 \mu \mathrm{s})$ and $10 / 700 \mu \mathrm{s}(5 / 320) \mu \mathrm{s}$, respectively. It will inject test voltage up to $15 \mathrm{kV}$ and fully compliant with IEC 61000-4-5 standard [8]. The second equipment is insulating transformer (TF-2302P model). It is used to transfer electrical power from an AC source to some equipment or device while isolating the powered device from the power source, usually for safety reasons. It provides galvanic isolation and used to protect against electric shock, to suppress electrical noise in sensitive devices, or to transfer power between two circuits which must not be connected. The test jig is used for lightning surge test as a connector between electrical devices cable and simulator machine cable.

\section{B. Experimental Setup}

Fig. 1 shows schematic diagram of lightning surge test for AC power line. The test object (equipment under test/EUT) is put on the jig and connected to the surge immunity simulator unit. Additional fax equipment is used to check the EUT whether can perform two ways communication during the test. A loop simulator is used as an indicator the EUT and additional fax unit can communicate properly. While, Fig. 2 shows the schematic diagram of lightning test for telecommunication line. The test objects (EUT) in this work are three types of electrical devices, namely multi-function printer, laser fax, and integrated telephone systems, respectively. Each device is consisting of 10 units for testing purpose. Figs. 3 and 4 show the actual picture of lightning surge test for AC power and telecommunication lines.

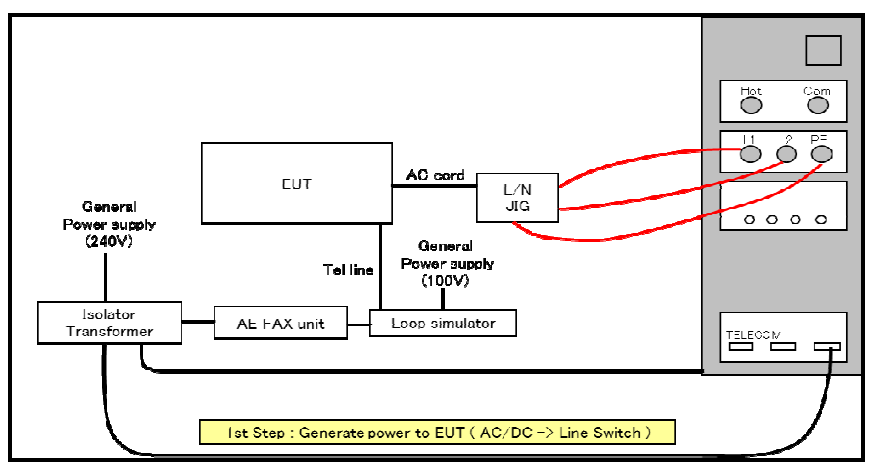

Fig. 1. Schematic diagram of lightning surge test for AC power line.

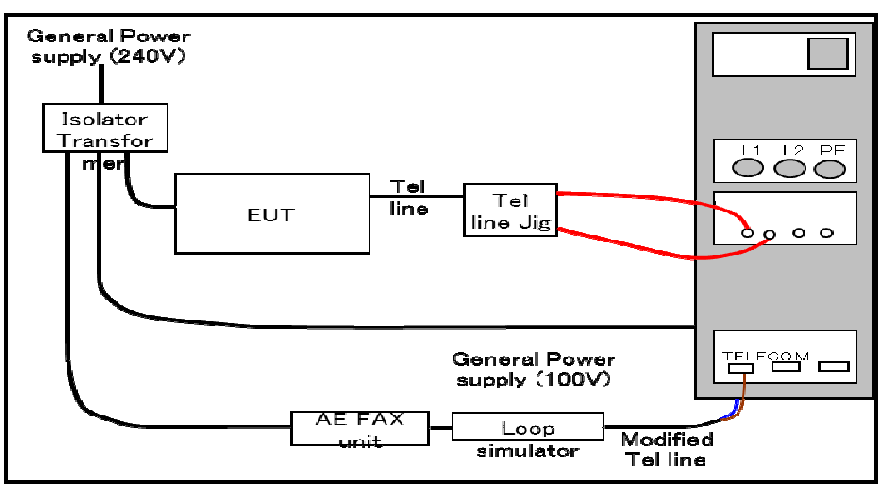

Fig. 2. Schematic diagram of lightning surge test for telecommunication line.

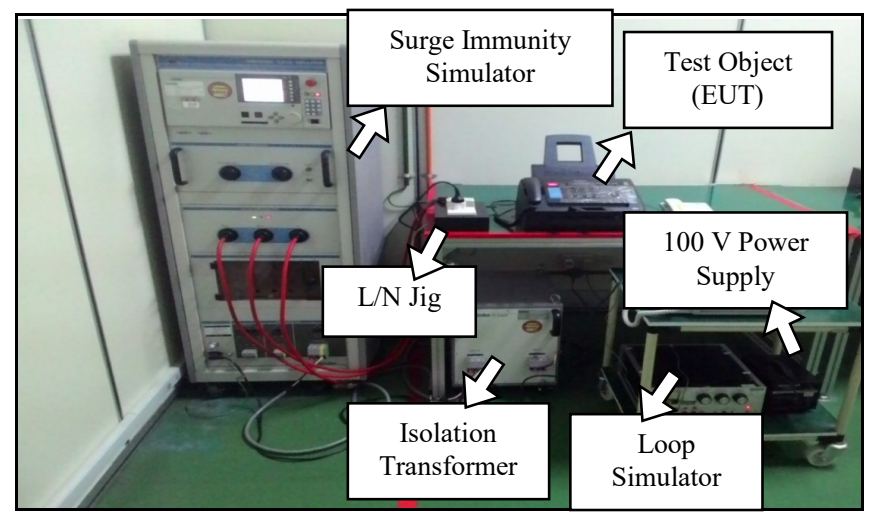

Fig. 3. Actual picture of lightning surge test for AC power line.

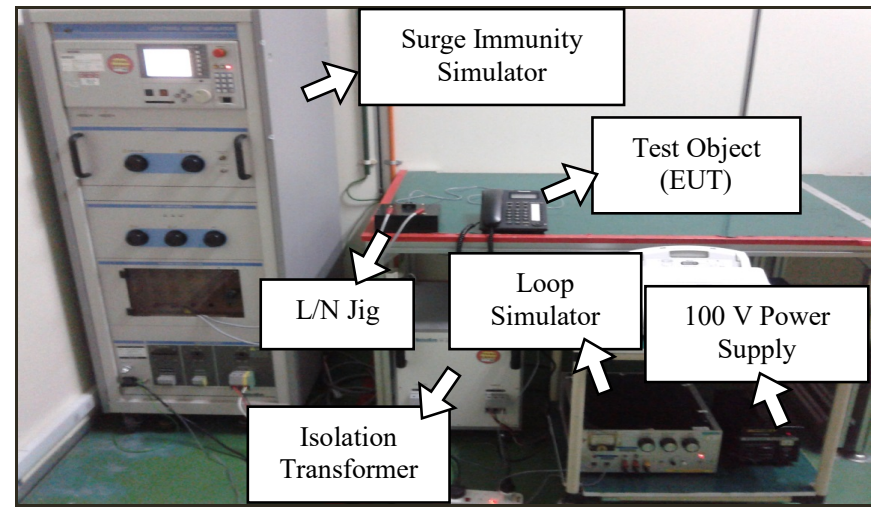

Fig. 4. Actual picture of lightning surge test for telecommunication line.

\section{RESULTS AND DISCUSSION}

There are 30 units of electrical devices under test (EUT) in this research work. They are multi-function printer, laser fax, and integrated telephone systems (10 units each). From these totals of 30 units, only 7 units $(23.3 \%)$ were observed to have abnormal performance and condition when injected with surge voltage in an increasing value. The others unit of electrical devices were observed to have normal performance when injected with the maximum surge voltage from the lightning surge simulator up to $15 \mathrm{kV}$. Table 1 shows the detail of experimental result.

The performance criteria that were recorded from the observation towards electrical devices under surge immunity are categorized as follows. A is for normal performance, B is for degradation performance, $\mathrm{C}$ is for temporary lost function performance, and $\mathrm{D}$ is for totally lost function performance (damaged). Fig. 5 shows the experimental result of lightning surge test for $\mathrm{AC}$ power line for all test objects (EUT) according to their performance criteria. It can be seen that multi-function printer had high possibility to damaged when subjected to surge voltage compared with other devices.

Fig. 6 shows the experimental result of lightning surge test for telecommunication line for all test objects (EUT) according to their performance criteria. It was found that no damaged performance (D criteria) was found on all test objects under this test. It can be seen that the integrated telephone systems had high ability to the temporary loss function ( $\mathrm{C}$ criteria) compared with other two devices. 
TABLE I. Result of Lightning Surge Test for All Test OBjects (EUT)

\begin{tabular}{ccc}
\hline Devices & Number & Abnormality performance \\
\hline Multi-function printer & 10 & 3 \\
Laser fax & 10 & 2 \\
$\begin{array}{c}\text { Integrated telephone } \\
\text { system }\end{array}$ & 10 & 2 \\
Total: & 30 & 7 \\
\hline
\end{tabular}

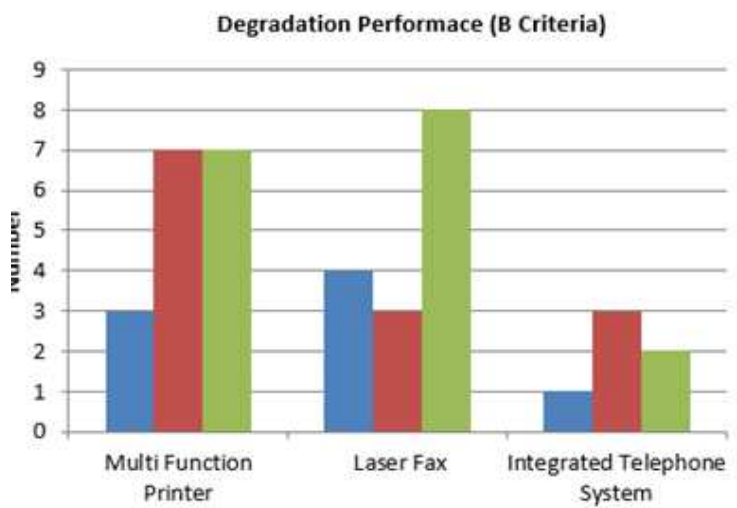

(a)

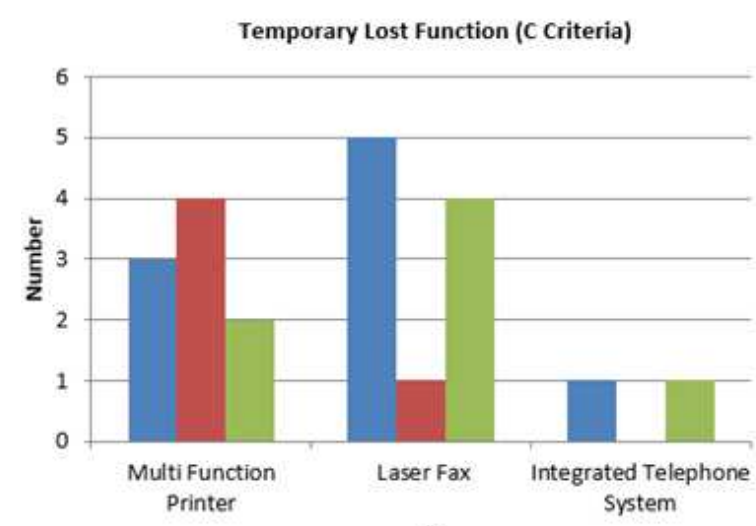

(b)

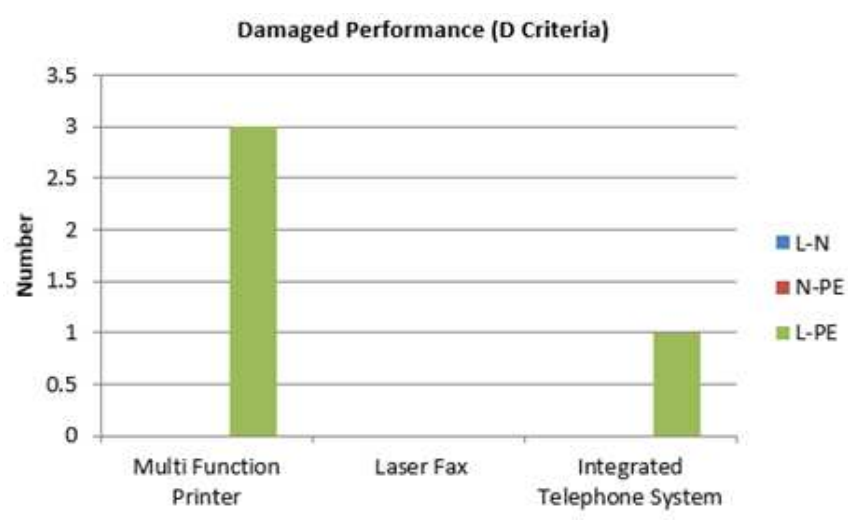

(c)

Fig. 5. Results for lightning surge test for AC power line.

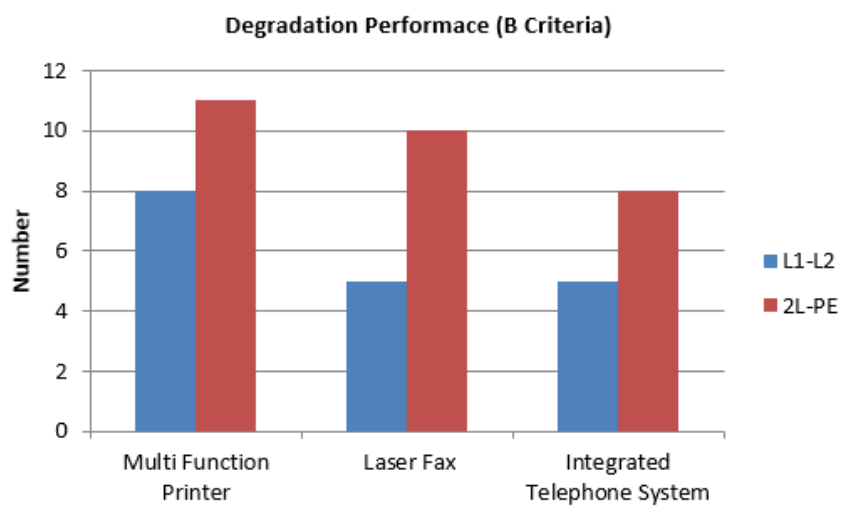

(a)

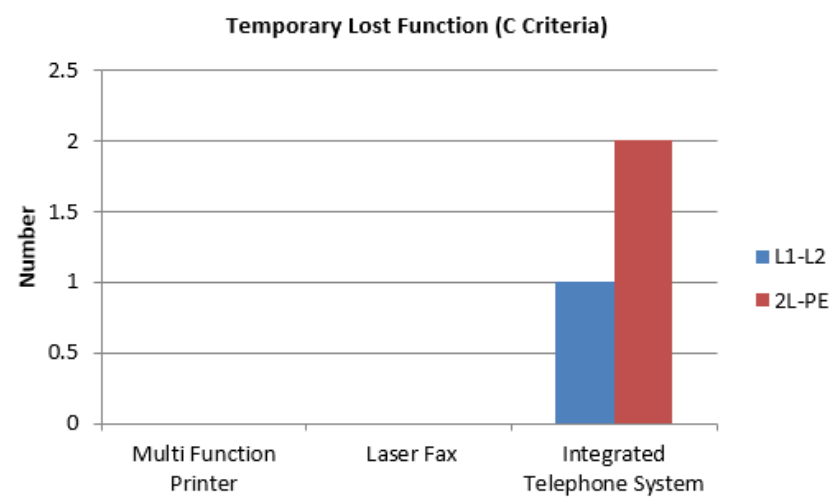

(b)

Fig. 6. Results for lightning surge test for telecommunication line.

From data analysis, it can be concluding that the high functional devices such as multi-function printer had the lowest immunity to the lightning surge compared with laser fax and integrated telephone systems. Multi-function printer had more functional working operation such as copy, scan, print, receiving and transmitting process compared to laser fax which only has receiving and transmitting function and integrated telephone systems which had on hook and off hook function. As an example, at case 3, multi-function printer cannot withstand the surge voltage at $13 \mathrm{kV}$ and it performance already totally lost function and damaged compared with other devices which are still in good function at this level of voltage surge. From analysis result, it was found that $(+)$ polarity has high possibility to degrade faster compare to (-) polarity.

As an example of this case, multi-function printer was starting to degrade at $4 \mathrm{kV}$ for $(+)$ polarity compared with () polarity which starting to degrade at $5 \mathrm{kV}$. The different between $(+)$ polarity and (-) polarity is the flow of electron. For $(+)$ polarity, electron will flow from test object (EUT) to the surge simulator. The EUT then will try to find the source (such as grounding) to supply electron to surge simulator. For (-) polarity, electron will flow from surge simulator to the EUT. The electron which gathers inside the surge simulator will flow to the EUT. This work shows that the worst and high probability for damage occurred toward coupling/decoupling network is at common mode which are L-PE \& N-PE coupling. From data experiment, it is found 
that the degradation and lost function occur to the devices if there were some narrow coincidence between the phase angle of waveform and superposition of surge. By doing analysis from the data obtain, it was found that the degradation and lost function frequently occur at phase angle $90^{\circ}$ and $270^{\circ}$, respectively.

\section{CONCLUSION}

The experimental investigation on effect of lightning surge in AC power and telecommunication lines for electrical devices has been successfully performed in this research work. In lightning surge test for AC power line, multi-function printer has high possibility to damage when subjected to voltage surge compared with other devices. While, for telecommunication line, it was observed that the integrated telephone systems have high possibility to the temporary loss function (C criteria) compared with other two devices.

This research work also found that the worst and high probability for damaged to occur toward coupling/decoupling network is at common mode, which are L-PE \& N-PE couplings. From experimental data result, it is shown that the degradation and lost function occur to the devices if there were some narrow coincidence between the phase angle of waveform and superposition of surge.

\section{ACKNOWLEDGMENT}

The authors would like to thank Universiti Malaysia Sarawak (UNIMAS) for the financial support under Small Grant Scheme (F02/SGS/1784/2018) facilitation and support in completing this research work.

\section{REFERENCES}

[1] Stimper K, Ackerman G, Ehrler J, Scheibe, K. "Transient overvoltages in low-voltage systems-A field study in Germany". IEEE Electrical Insulation Magazine, 1998, vol. 14, pp.15-22, April 1998.

[2] Standler, R.B. "Transients on the mains in a residential environment, "IEEE Transactions on Electromagnetic Compatibility, vol. 31. pp. 170-176, February 1989.

[3] S.B Smith and R. B. Standler, "The effects of surges on electronic appliances," IEEE Transactions on Power Delivery, vol. 7, Issue 3, pp. 1275-1282, July 1992.

[4] Lightning and surge protection, http://www.msystem.co.jp/mssenglish/service/emmrester.pdf

[5] Henry W. Ott, Henry Ott Consultants, Electromagnetic Compatibility Engineering. EMC notebook. 2009.

[6] Lightning and surge protection, http://www.msystem.co.jp/mssenglish/service/emmrester.pdf

[7] K. Ermeler, W. Pfeiffer, D. Schoen and M. Schocke, "Surge immunity of electronic equipment". IEEE Electrical Insulation Magazine, vol. 16, pp. 12-16, February 2000.

[8] IEC 61000-4-5:2005, Electromagnetic compatibility (EMC)-Part 4-5: Testing and measurement techniques - Surge immunity test. 